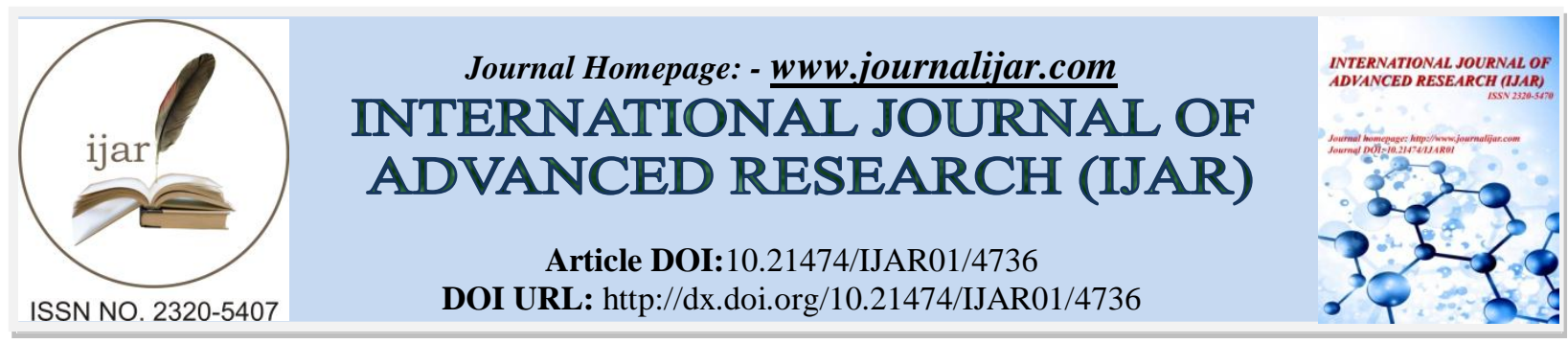

RESEARCH ARTICLE

\title{
USE OF TIE-IN CONFIGURATION TECHNIQUE IN THE REPAIR OF FEMORAL AND HUMERAL DIAPHYSEAL FRACTURES IN DOGS.
}

\author{
J. Radhakrishna Rao, V. Gireesh Kumar, T. Madhava Rao, D. Pramod Kumar, K. Chandra Shekar Reddy \\ and K.B.P. Raghavender.
}

Department of Veterinary Surgery and Radiology, College of Veterinary Science, P. V. NarsimhaRaoTelangana Veterinary University, Rajendranagar, Hyderabad-500030.

\section{Manuscript Info}

\section{Manuscript History}

Received: 4 May 2017

Final Accepted: 6 June 2017

Published: July 2017

Key words:-

tie-in configuration, femoral and humeral fractures, dogs.

\section{Abstract}

In this study Tie-in pin configuration technique was employed in the stabilization of 5 femoral fractures and 1 bilateral humeral fracture in dogs. Immediate postoperative radiographs revealed good alignment and apposition of the fracture fragments in all the dogs. The mean time of sufficient callus formation was $43.16 \pm 4.46$ days. Postoperative radiographs showed restitution of cortico-medullary continuity by $45^{\text {th }}$ to $55^{\text {th }}$ postoperative day in all the dogs. The complete weight bearing was ranging from $32^{\text {nd }}-90^{\text {th }}$ postoperative day. The fixator was found rigid and stable till the completion of bone healing in all the dogs. The mean time of the fixator removal was $43.16 \pm 4.46$ days. Pin tract infection with appearance of granulation tissue in one dog was seen at the intramedullary pin exit site. Tie-in pin configuration technique was well suited for the repair of femoral and humeral diaphyseal fractures in dogs with a few negligible minor complications

Copy Right, IJAR, 2017,. All rights reserved.

\section{Introduction:-}

Long bone fractures are common in dogs. Among all long bone fractures, femoral fractures are frequently encountered (Ben Ali, 2013 and Simon et al., 2010). Humeral fractures are less common (Aithalet al., 1999). These fractures usually occur due to the trauma in the form of road side accidents. Intramedullry Pinning (IM) is still most frequently used method of femoral and humeral fracture fixation in dogs (Piermatteiet al., 2006 and Fossum, 2007). Intramedullary pins have biomechanical advantage of neutralizing bending forces acting on the fracture fragments (Johnson 2007). However, intramedullary pins cannot counter the torsionaland axial compressive loads effectively. Intramedullary pinning may be supplemented with Type Ia External Skeletal Fixator (ESF) to resist these forces. Without tie-in of intramedullary pin with Type Ia ESF, the intramedullary pin may migrate proximally and lead to instability of fracture fixation. Hence the Type Ia ESF may be tied in to a small (in diameter) intramedullary pin that fills approximately 40-60\% of the medullary cavity which is called a tie-in configuration (Aron, 1998; Denny and Butterworth, 2006; George et al., 2006; Radkeet al., 2006; Adamiaket al., 2007, Worth, 2007; Allah et al., 2009; Ayyappanet al., 2009; Boghossian and Boghossian, 2010, Pisaniet al., 2010, Fossum, 2013 and Toombs, 2014). These frames are generally applied to the lateral aspect of femur and humerus. Tie-in configuration neutralizes the bending forces and also controls such rotational forces and so provides excellent stability. It also prevents proximal migration of IM pin as well. 
Hence Tie-in pin configuration can be used clinically to manage diaphyseal fractures of femur and humerus. The objective of the present study was to evaluate the efficacy of Tie-in pin configuration in the repair of femoral and humeral fractures of dogs.

Materials and Methods

Six dogs of different breed, age, sex and body weights were presented to the Veterinary Clinical Complex, P.V. Narsimha Rao Telangana Veterinary University(PVNRTVU), Hyderabad, Telangana state, with fractures of long bones (femur and humerus), were first examined as a clinical routine and if any soft tissue injuries were present also recorded. The dogs were also observed for loss of function, abnormal mobility, deformity or change in angulation of the affected limb, signs of local swelling, pain and crepitation at the fracture site (Fig.1). Neurological status of the dog was assessed and the dogs with neurological signs were excluded from the study.

The dogs were prepared aseptically for the surgery and general anaesthesia was induced with Ketemine and Xylazine at the rate of $10 \mathrm{mg} / \mathrm{Kg}$ and $1.0 \mathrm{mg} / \mathrm{Kg}$ body weight, respectively, intramuscularly and the anaesthesia was maintained by giving incremental doses of Propofol at the rate of $4 \mathrm{mg} / \mathrm{Kg}$ body weight intravenously.

Patient preparation and positioning was done as per the standard procedure outlined by Harasen (2003), Piermatteiet al. (2006), Fossum (2013) and Toombs (2014). The femoral fractures were reduced with open approach in all the dogs on lateral recumbency with the affected limb up. Tie-in configuration method was employed for fixation of humerus and femoral fractures. For Tie-in configuration, the bone diameter visualized on the radiograph along with the body weight of the animal was considered for selecting the size of the pins (Butterworth, 1993). Trocar pointed stainless steel Steinmann pins of appropriate size so as to fit $40 \%$ of medullary canal were used as intramedullary pins and Jacob's chuck was used to place the IM pin in retrograde manner to align and appose the fractured segments of concerned bones and cerclage wiring was used wherever necessary to reduce the fracture fragments. The linear type Ia external skeletal fixator was applied on the lateral aspect of the femur by placing trocar pointed two or three 2.0-3.0 mm positive profile pins after making releasing skin and soft tissue incisions using no. 11 scalpel blade in such a way that they pass through both the cortices till the trocar point of the pin just exited from the opposite cortex of the femur. The pins were connected to the connecting rod of $4 \mathrm{~mm}$ size with clamps. The linear type Ia fixator was then tied to the projected IM pin by a small connecting rod with clamps to complete Tie-in configuration. The pin cutter was used to cut the excess length of transfixation pins, IM pin and connecting bars. In one dog with bilateral humeral fracture, the patient preparation, positioning and approach for humerus was adopted as per the standard procedure outlined by Harasen (2003), Piermatteiet al. (2006), Fossum (2013) and Toombs (2014). The material and the procedure of application of tie-in construct was as specified by Fossum (2013) and Toombs (2014).

In fractures of humerus, open approach was followed in all the cases for reduction and IM pin application. The incision was made on the cranial border of the tubercle of the humerus to the lateral epicondyle distally. The subcutaneous fat and the brachial fascia were incised along the same line. The cephalic vein was carefully isolated and protected. The brachial fascia was incised along the cranial border of the brachiocephalicus muscle and the lateral head of the triceps muscle. The radial nerve was visualised and isolated. An incision was made through the periosteal insertion of the superficial pectoral and brachiocphalicus muscles of their insertion on the humeral shaft. These two muscles and brachialis muscle were reflected caudally and exposed the humeral shaft. Further to gain access of the distal shaft of the humerus the brachialis muscle was reflected cranially and the lateral head of the triceps muscle caudally. The origin of the extensor carpi radialis muscle was reflected from the ridge of the lateral epicondyle of the humerus for minimum exposure. The fracture fragments were reduced by placing IM pin in retrograde fashion. The linear external skeletal fixator was applied on the lateral aspect of the humerus by placing trocar pointed two or three 2.0 -3.0 mm positive profile pins after making releasing skin and soft tissue incisions using no. 11 scalpel blade in such a way that they pass both the cortices till the trocar point of the pin just exited from the opposite cortex of the humerus. The pins were connected to the connecting rod of $4 \mathrm{~mm}$ size with clamps. The linear fixator was then tied to the IM pin by a small connecting rod with clamps. The brachiocephalicus and superficial pectoral muscles were sutured to the fascia of the brachialis muscle. The subcutaneous tissue was suture using No. '0' chromic cat gut. The skin was sutured using No. '0' synthetic polyamide with horizontal mattress sutures (Fossum, 2013 and Toombs, 2014).

In the present study, cleaning with normal saline and dressing of the pin and skin interface with 5\% povidone iodine pads was found effective in rendering the sites clean and sterile in all the groups of dogs and Inj. 
CefetoximeSodium ${ }^{1}$ was administered at the rate of $20 \mathrm{mg} / \mathrm{kg}$ body weight as intramuscular injection twice daily for one week post operatively. Antibiotic therapy was prolonged for 3 to 5 more days whenever needed. Inj. Meloxicam $^{2}$ was administered at the rate of $0.2 \mathrm{mg} / \mathrm{kg}$ body weight as intramuscular injection once daily pre operatively and post operatively for four days and was prolonged for 3 to 5 more days whenever needed. Owners were advised to monitor the position of construct and to restrict the movement of the animal for 2 weeks after surgery and then to allow leash walking.

Clinical evaluation was routinely carried out at periodical intervals for the signs of swelling, exudation, weight bearing and stability of the fixator in all the dogs. Radiographs were obtained immediately after Tie-in configuration of femoral and humeral diaphyseal fractures and on $15^{\text {th }}, 30^{\text {th }}, 45^{\text {th }}$ and $60^{\text {th }}$ postoperative day and whenever possible on later dates, to evaluate bone healing. The external skeletal fixator was removed when primary callus was formed leaving the IM pin in-situ after cutting the pin to the skin level till the completion of bone healing as a part of staged disassembly or the entire fixator was removed as one time removal after sufficient callus formation.

\section{Results and Discussion:-}

In this study Tie-in configuration was combined with intramedullary pinning in reduction of fracture fragments in femoral and humeral fractures and it was tied-in with Linear type Ia ESF (Ayyappanet al., 2009; Boghossian and Boghossian, 2010, Pisaniet al., 2010 and Toombs,2014)

1. Taxim injection - Alkem laboratories Ltd. Mumbai.

2. Melonex injection - Intas Pharmaceuticals Ltd. .Ahmedabad.

Preoperative radiographs of the 6 dogs revealed transverse fractures of femur in 2 dogs, femoral neck fracture of femur in one dog, proximal comminuted fracture of femur in one dog and oblique fracture of femur in one dog and bilateral oblique fracture of humerus in one dog. All the dogs had closed fractures.Lateral approach for femur and humerus, found appropriate for theeasy application of linear fixator (Type Ia) and tie-in with the IM pin thereafter. Good anatomical reduction was achieved by applying IM pin alone in 5 dogs and by applying IM pin and cerclage wire in 1 dog.Fossum (2013) also suggested use of cerclage wire to support long oblique fractures and spiral fractures. Discharge from pins, decreased after few days postoperatively. Discharge from IM pin exit site observed in one dog till the removal of the fixator. The tolerance of fixator was good in all the dogs. The stability of the fixator was good in all the dogs (Van Ee and Geasling., 1992), Butterworth, (1993), Harariet al., 1998) and George et al., 2007).

The dogs in this study showed partial weight bearing from $3^{\text {rd }}-6^{\text {th }}$ postoperative day in all the dogs. Fixator dependent lameness observed in 3 dogs due to pain and all the dogs showed complete weight bearing 3-5 days after removal of the fixator. All the dogs exhibited pain because of the movement of the IM pin as it was loose and tied to the ESF (George et al., 2007 and Vedpathaket al., 2011). The complete weight bearing was ranging from $30^{\text {th }}-90^{\text {th }}$ postoperative day (Fig.2). The mean time of complete weight bearing was ranging from $41.33 \pm 4.33$ day (Harariet al., 1996) Table 1.

Immediate postoperative radiographs revealed good alignment and apposition of the fracture fragments in all the dogs (Langley-Hobbs 2003and Piermatteiet al., 2006) (Fig.3 and 4). The immobilization of fracture fragments was good in all the cases. Progressive bone healing was observed in post operative radiographs (Fig.5). Callus formation was seen on $15^{\text {th }}$ post-operative day with distinct fracture line. Primary callus formation was seen from $30^{\text {th }}-45$ th postoperative day. At this time the linear fixator ie. Type Ia ESF was removed. Appearance of callus with adequate radio-density was observed from $30^{\text {th }}$ day to $55^{\text {th }}$ post-operative day. At this time the IM pin was removed (Allah $e t$ al., 2009 and George et al., 2006). The mean time of sufficient callus formation in this group was $43.16 \pm 4.46$ days (Ayyappanet al. 2009, Boghossian and Boghossian, 2010 and Pisaniet al. 2010).

Staged disassembly was performed in two cases on $30^{\text {th }}$ and $45^{\text {th }}$ postoperative day, where linear external skeletal fixator was removed after formation of primary callus and the intramedullry pin was removed 2 weeks there after (Hurov and Seer, 1968; George et al. 2006; George et al. 2007; Shales 2008a and Vedpathaket al, 2011). The tie-in configuration was removed between 30 days to 55 days with mean time of removal $43.16 \pm 4.46$ days. In the present study, the entire tie- in construct was removed in 4 cases without staged disassembly under general anaesthesia (Ayyappanet al. 2009, Boghossian and Boghossian, 2010 and Pisaniet al. 2010). The day on which the ESF assemblies were removed is presented in table 2 . 
Complications noticed were discharge from IM pin exit site till linear fixator removal was observed in one dog which decreased and stopped thereafter. In one dog, the discharge was seen till the entire tie-in construct removal (Ayyappanet al., 2009 and Boghossian and Boghossian, 2010). Minor pin tract discharge with growth of granulation tissue at IM pin exit site was noticed in one dog which subsided afterwards (Kraus et al., 2003). Wounds due to the pressure exerted by the fixator were observed in one dog (Kraus et al. 2003).Migration of IM pin was seen in one dog with femoral fracture and in one dog with bilateral humerus fracture after staged disassembly. These were minor complications and did not affect the outcome of the patient.

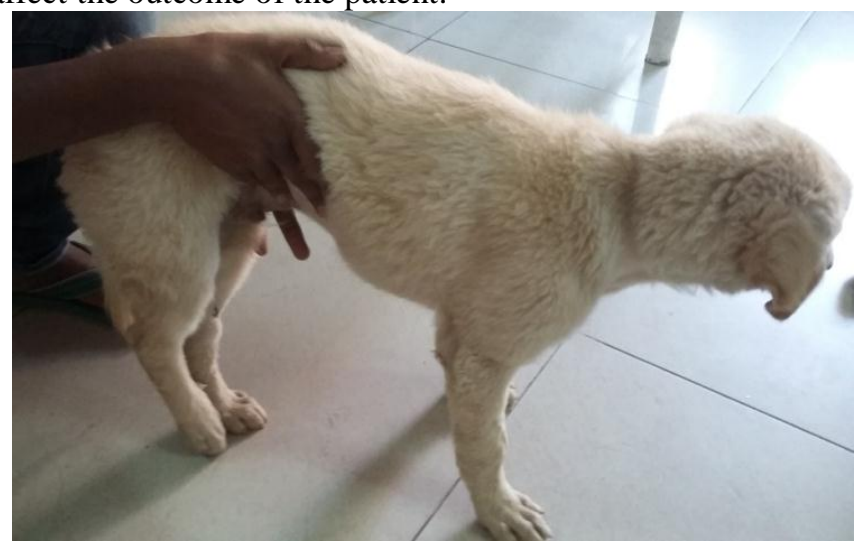

Fig. 1:-Dog showing dangling and non weight bearing on hind limb.
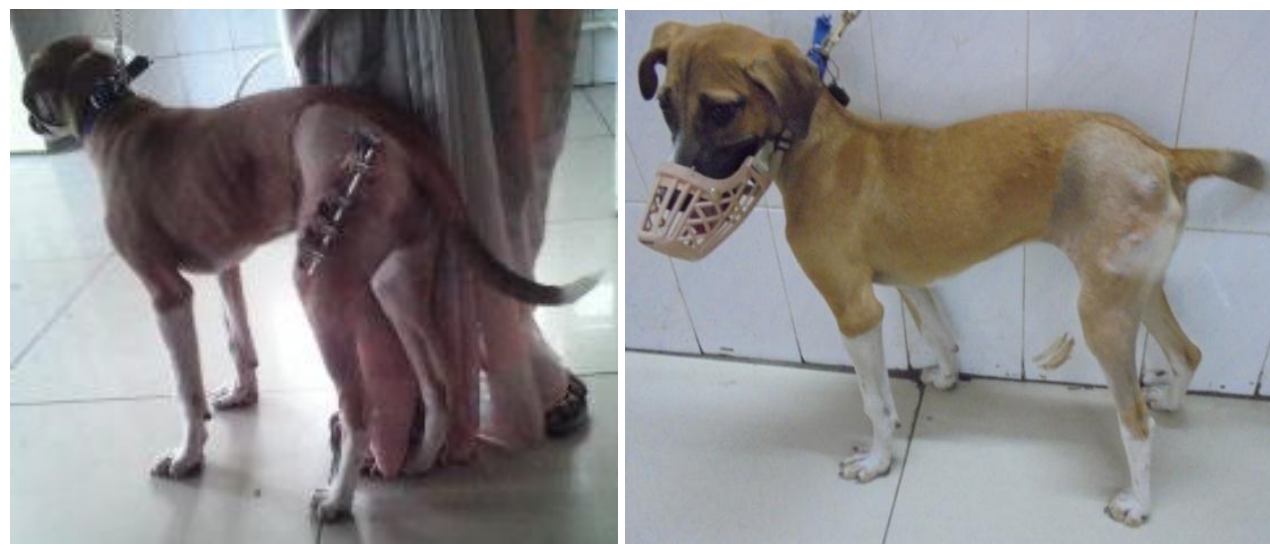

Fig. 2:- Postoperative complete weight bearing.
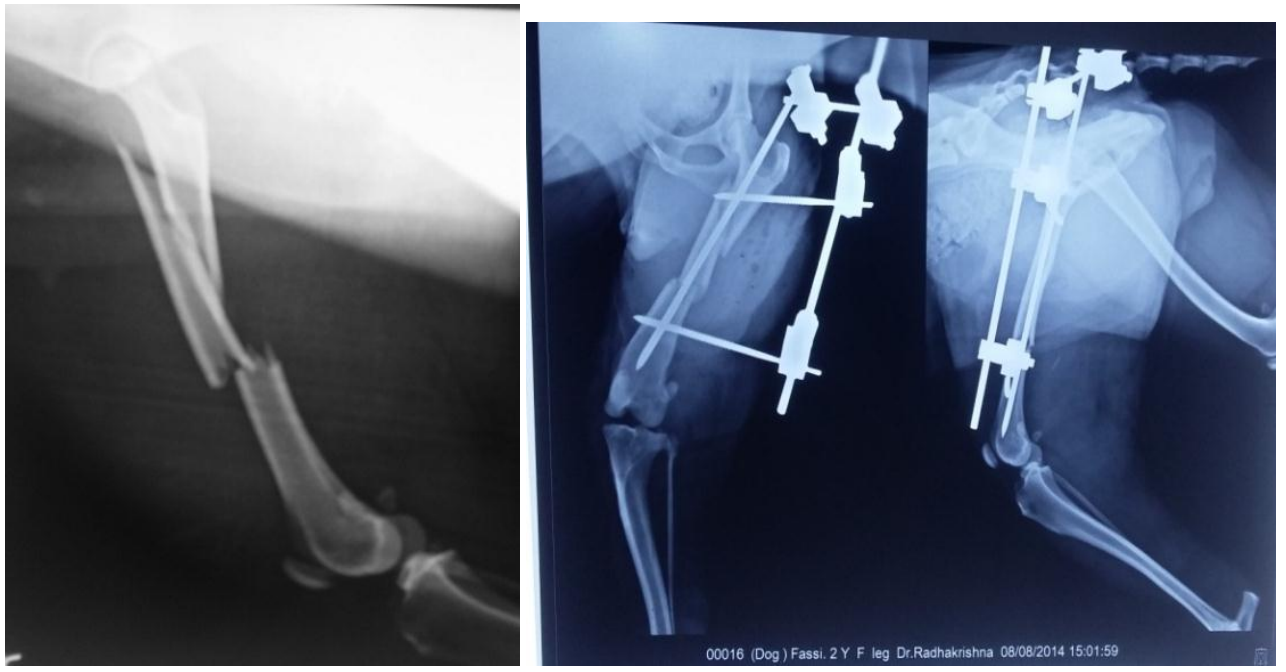

Fig.3:- Pre and post-operative radiographs of comminuted femoral fracture in a GSD dog showing proper alignment 


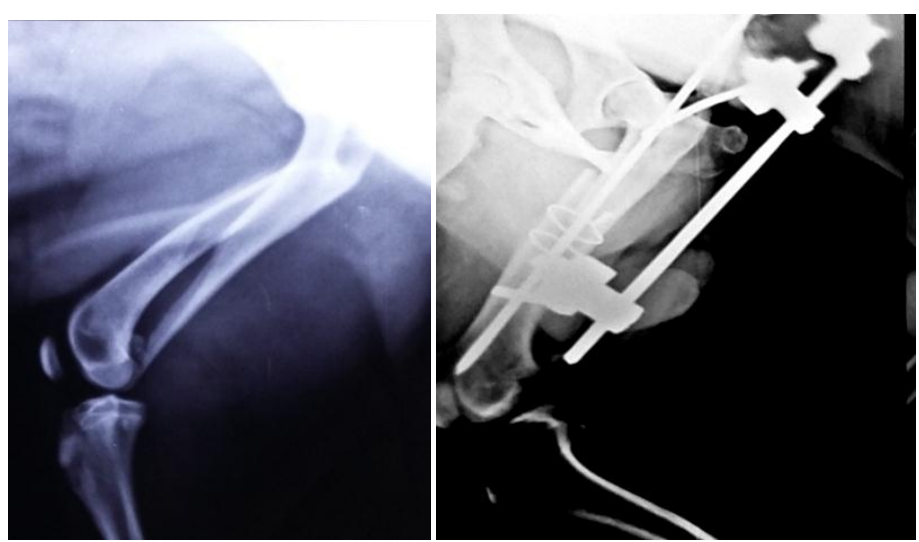

Long oblique fracture of femur, showing, proper alignment of fracture Fragments Fig.4:- Pre and Post-operative Radiographs of long oblique Femoral Fracture Showing Proper Alignment

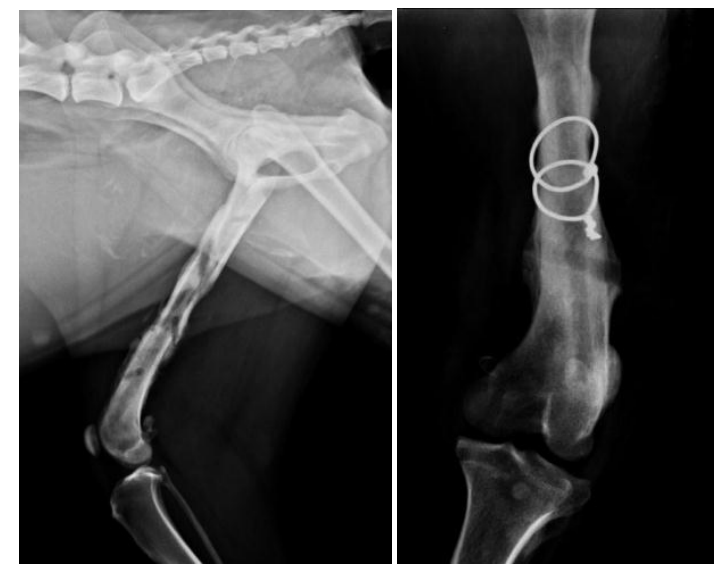

Fig.5:- Pre and post-operative radiographs of femoral fractures showing progressive bone healing

Radiograph showing completed bone healing and progressive establishment ofcortico-medullary continuity after removal of IM pin in Tie-in pin configuration on $45^{\text {th }}$ post-operative day

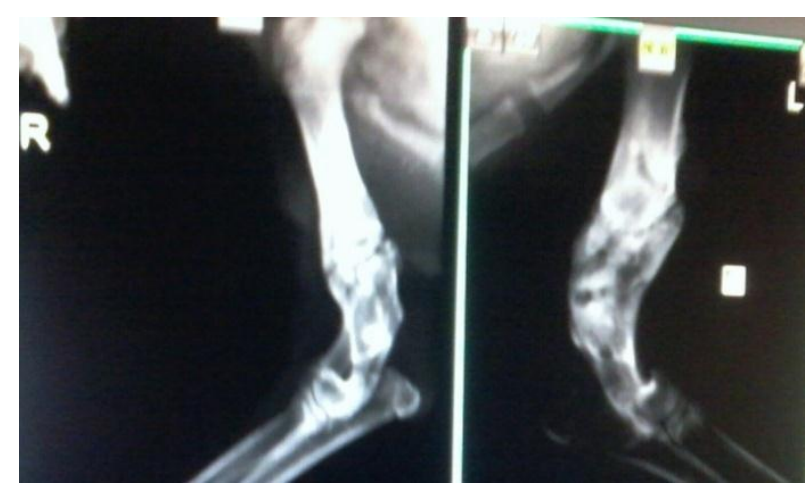

Fig. 6:- Progressive bone healing in Bilateral Humerus Fracture in a Labrador Pup

Note. Gradually disappering fracture line and the bridging callus becoming radio-dense 
Table 2:- Table showing postoperative details of lameness score

\begin{tabular}{|c|c|c|c|c|c|c|}
\hline Case No. & Pre-operative & \multicolumn{5}{|c|}{ Post-operative Weight Bearing at the end of } \\
\cline { 3 - 7 } & & 1 Week & 2 Week & 4 Week & 6 Week & Full weight bearing observed \\
\hline 1. & 1 & 2 & 3 & 4 & 4 & 45 th day \\
\hline 2 & 1 & 2 & 3 & 3 & 4 & 90 th day \\
\hline 3 & 1 & 2 & 3 & 3 & 3 & 60 th day \\
\hline 4 & 1 & 2 & 3 & 2 & 2 & 37 th day \\
\hline 5 & 1 & 2 & 3 & 3 & 4 & 32 nd day \\
\hline 6 & 1 & 2 & 3 & 4 & 4 & 42 nd day \\
\hline Mean & $1.0 \pm 0.0$ & $2.0 \pm 0.0$ & $3.0 \pm 0.0$ & $3.16 \pm 0.30$ & $3.5 \pm 0.34$ & $41.33 \pm 4.33$ day \\
\hline
\end{tabular}

1. No functional limb usage; limb carried most of the time,

2. Slight functional limb usage; limb carried during running but set down when walking,

3. Moderate functional limb usage and partial weight bearing; lameness evident,

4. Complete, normal functional limb usage.

Table3:- Table showing time of removal of fixator.

\begin{tabular}{|c|c|c|}
\hline \multicolumn{3}{|c|}{ Group III } \\
\hline \multirow{2}{*}{ Case No. } & ESF & Days of ESF Removal \\
\cline { 2 - 3 } & 32 & 32 \\
\hline 1 & 53 & 53 \\
\hline 2 & 30 & 39 \\
\hline 3 & 45 & 55 \\
\hline 4 & 50 & 50 \\
\hline 5 & 30 & 30 \\
\hline Mean & $40.00 \pm 4.31$ & $43.16 \pm 4.46$ \\
\hline
\end{tabular}

\section{Conclusions:-}

The Tie-in configuration was well tolerated by all the dogs and showed remarkable improvement in limb function with good fixator stability till the completion of bone healing. Use of cerclage wiring improved the stability of the fracture fragments in long oblique fractures of femur in the study. The Tie-in configuration can be considered for fracture stabilization of femoral and humeral fractures in dogs. This is a biomechanically versatile technique and easy to apply, well tolerated by the patient, easy to disassembly, counteracts bending and rotational forces acting on fracture fragments.

\section{Acknowledgements:-}

Authors are thankful to P. V. NarsimhaRaoTelangana Veterinary University, Rajendranagar, Hyderabad, India, for providing necessary facilities to carry out this research work.

\section{References:-}

1. AdamiakZ Aleksiewicz R, Kostrzewski M and Moderski J 2007. Comminuted Long bone fractures in cats caused by pneumatic gunshot and repaired using the external fixator "tie-in" technique. Polish Journal of Veterinary Science, 10: 153-157.

2. Aithal H P, Singh G R and Bisht G S 1999. Fractures in Dogs: A Survey of 402 Cases. Indian Journal of Veterinary Surgery. 20(1): 15-21.

3. Allah S M G, Farghalli H and Magdi A 2009. Combined different fixation systems for reconstruction of comminuted diaphyseal fracture in dogs. Veterinary Medical Journal Giza. 57(4): 525-541.

4. Aron D N 1998. Practical techniques for fractures. In: current techniques in small animal surgery Bojrab M J. IV ed. William and Wilkins Baltimore. 872-873.

5. Ayyappan S, ShafiuzamaMd, Ganesh T N, Das B C and Kumar R Suresh 2009. A Clinical Study on External Fixators for Long Bone Fracture Management in dogs. Indian Journal of Veterinary Surgery. 30(2): 90-92.

6. Ben Ali 2013. Incidence, occurrence, classification andoutcome of small animal fractures: A retrospective study (2005- 2010). World Academy of Science,Engineering and Technology. Vol.7. No.3-27. 
7. Boghossian M and Boghossian V 2010. Use of meynard clamps in external skeletal fixator with intramedullary tie-in pin for the treatment of femoral fractures in dogs and cats A four case report. 15th Annual European ESVOT Congress, Bologna. Italy WVOC. 644- 645.

8. Butterworth S 1993. Use of External Fixators for Fracture Treatment in Small animals. In Practice. 15: 183-192.

9. Denny H R and Butterworth S J 2006. A Guide to Canine and Feline Orthopaedic surgery. IV ed. Blackwell science Ltd 99.

10. Fossum T W 2007. Small Animal Surgery. III ed. Mosby Elsevier, Missouri USA. 930-931.

11. Fossum, T. W. 2013. Small Animal Surgery. IV ed. Mosby Elsevier, Missouri USA. 930-931.

12. George C, Nagarajan L, Manohar B M 2006. "Tying-in” of intramedullary pin with stainless steel external skeletal fixator to prevent pin migration in a dog. Indian Journal of Veterinary Surgery. 27 (2): 132.

13. George C, Nagarajan L, Manohar B M 2007. Stainless steel and acrylic external skeletal fixators as adjuncts to intramedullary pinning for femoral fracture repair in dogs. Indian Journal of Veterinary Surgery. 28(1): 37-38.

14. Harari, J., Bebchuk, T., Seguin, B., and Lincoln, J. 1996. Closed Repair of Tibial and Radial Fractures with External Skeletal Fixation. The Compendium Small Animal Continuing Education. 18: 23-29.

15. Harari J, Seguin B and Padgett S L 1998. Principles of External Skeletal Fixation in Small Animal Surgery. Veterinary Medicine. 93: 445-453.

16. Harasen, G. 2003. Common long bone fracture in small animal practice-Part 2. Canadian Veterinary Journal. 44: 503504.

17. Hurov L and Seer G 1968. External Kirschner Clamp Fixation with intramedullary pinning for distal femoral epiphyseal fracture repair. Canadian Veterinary Journal. 9(2): 31-40.

18. Johnson A L 2007. Tibial and fibular diaphyseal fractures. In Text book of small animal surgery Slatter D. III ed. Cheryl S Hedlund. 1126-1142.

19. Kraus K H, Toombs J P and Ness M G 2003. External Fixation in Small Animal Practice. I ed. Blackwell Science Ltd Oxford UK. 21- 26.

20. Langley-Hobbs, S. 2003. Biology and Radiological Assessment of Fracture Healing. In Practice. 25: 26-35.

21. Piermattei, D., Flo G and DeCamp, C. 2006 Handbook of Small Animal Orthopedics and Fracture Repair. IV ed. Elsevier Inc Missouri USA. Pp. 49-94.

22. Pisani G, Pauludi G, Sangion F, Penazzi C and Peirone B 2010. Femoral fracture treatment in cat with "tie-in" technique: clinical experience in 25 cases. Veterinaria(Cremona). 24(5): 7-17.

23. Radasch, R. M., Lewis, D. F., McDonald, D. E., Calfee, E. F., and Barstad, R. D. 2008. Pesvarus correction in dachshunds using a hybrid external fixation. Vet. Surg. 37: 71-81.

24. Radke H, Aron D N, Applewhite A and Zang G 2006. Biomechanical analysis of unilateral external skeletal fixators combined with IM- pin using finite-element method. Veterinary Surgery. 35(1): 15-23.

25. Shales C 2008a. Fracture Management in Small Animal Practice 1. Triage and Stabilization. In Practice. 30: 314320.

26. Simon S M, Ganesh R, Ayyappan S, Rao G D, Suresh Kumar R, Kundeve V R and Das C 2010. Incidence of pelvic limb fractures in dogs: A survey of 478 cases. Veterinary World. 3(3): 120-121.

27. Toombs, J. P., Bronson, D.G and Welch, R. D. 2014. Eternal Skeletal Fixation. In:Current Techniques in Small Animal Surgery, 5th edn. Teton NewMedia, USA, PP. 800-810.

28. VanEe R T and Geasling J W 1992. The Principles of External Skeletal Fixation. Veterinary Medicine. 87: $334-343$.

29. Vedpathak H S, Tank P H, Karle A S, Bhatia A and Desai B D 2011. Clinical evaluation of tie-in configuration and intramedullary pinning for stabilization of femoral fractures in dogs. Indian Journal of Veterinary Surgery. 32(2): 111-113.

30. Worth A J 2007. Management of fractures of the long bones of eight cats using external skeletal fixation and tied-in intramedullary pin with a resin-acrylic bar. Newzealand Veterinary Journal. 55(4): 191-197. 